\title{
Bayesian Semi-Parametric Modeling of Infertility in Nigeria
}

\author{
Onatunji Adewale Paul, \\ Lautech International College Ogbomoso, Oyo State \\ Folorunso Serifat Adedamola, \\ Department of Statistics, University of Ibadan, Oyo State \\ Oluwasola Timothy A. O., \\ Department of Obstetrics and Gynecology, \\ College of Medicine, University of Ibadan, Nigeria \\ Bamanga Muhammad Ardo, \\ Department of Mathematical Sciences, \\ Kaduna State University, Kaduna State \\ Folorunso Morufu Aderemi, \\ Federal School of Statistics, Ajibode, Ibadan, Oyo state
}

Doi:10.19044/esj.2019.v15n27p221 URL:http://dx.doi.org/10.19044/esj.2019.v15n27p221

\begin{abstract}
Infertility in Nigeria is a neglected reproductive health issue despite its negative impact. Majority of infertility-related research has focused on treating the consequences of infertility rather than investigating the determinants to explain the spatial and spline effect of infertility in the country. This work is aimed at investigating spatial variation of determinants of infertility among female in Nigeria. The finding reveals that women at reproductive age have a high probability of infertility in some southern part of Nigeria as their ages are steadily increasing. Also, change in the characteristics of place of residence and source of water increase the chance of woman being infertile. Policy makers on health sectors should make effort to address problems of climatic and atmospheric change in the identified social and demographic risk factors.
\end{abstract}

Keywords: Demographic-risk-factors, Health-sectors, Infertile, Reproductive-age, Spatial-Variations

\section{Introduction}

Infertility is a multifaceted medical and social problem affecting couples in Sub Sahara countries, defined as a serious handicap preventing people from realizing an important life goal or inability to produce a live birth. 
It is also linked with negative economic consequences and adverse impacts on mental and physical health. Research in sub-Saharan Africa suggested that women believed to be infertile are more likely to face social ostracization, marital instability and divorce, and verbal, emotional or physical abuse. Chelsea et.al ( 2017) found that close to one-third (31.3\%) of Nigerian couples exposed to the chances of pregnancy would have difficulty conceiving within 12 months, an estimate which is consistent with other, smaller studies in the region, by 24 months, this estimate dropped substantially to $17.7 \%$, and to $11.5 \%$ by 36 months. Infertility prevalence was higher among parous women and women over 35 years of age. Gnoth et al. (2005) reported that Infertility directly affected about one out of six couples and indirectly affected a much larger group of family members, considering characteristics of a couple of infertility. These characteristics are female or male factors implicated and in both. Determinants of infertility are socio demographic and lifestyles factors in women which were discussed in the literature. This infertility is as a result of sexually transmitted diseases, poor health care, poor lifestyle and female genital mutilation in Sub Sahara Africa (Wark et al 2009). It is important to note that sexually transmitted infection delays conception. Infection with gonorrhoea has also been linked with Pelvic Inflammatory Disease (PID) caused by Chlamydia and a subsequent higher risk of tubal factor infertility; fallopian tubes of women are particularly vulnerable to it and damage Khalaf(2003).

Bongaarts (1982) constructed models of human production to indicate four determinants, marriage/cohabitation, contraception, induced abortion and postpartum in fecundability as most important for the analysis of infertility. Cahill and Wardle (2002) showed that 54\% of couples infertility is attributable to female while $46 \%$ is attributed to male and unexplained cases of infertility after investigation. This reveals the evidence of burden of female infertility. There are two major medical causes of female infertility, ovulatory disorder and tubal factor problem, through which Evers (2002) revealed that approximately $25-30 \%$ of all female infertility is associated to ovulatory disorders and 11-30\% to tuboperintoneal factors.

\section{Materials and methods}

The dataset used in this study was secondary data from 2015 Nigeria DHS containing 6524 observations. This dataset includes 11 variables, both continuous and categorical in this study. Covariates include age of the woman, states of the origin, religion, place of residence, educational level, cooking, source of water, wealth index for women of reproductive age of 18-44 years old, married or cohabiting and sexually active not currently using contraception pills within the 12 months period of regular intercourse recorded dichotomously as response variable in the study. Where age of the woman 
and states of origin are continuous covariates that have nonlinear effect on infertility are modeled nonparametrically using penalized spline and spatial correlation of state of origin based on centroid coordinated. Other considered variables have fixed effect on infertility. The selected explanatory variables were correlated to binary response variable. The study adopts Bayesian inference for logistic regression parameters that uses the likelihood of woman reproductive status, prior for parameters to derive posterior density for woman reproducing offspring. BayesX statistical software is then used to carry out the analysis.

\section{Likelihood Function of Woman Reproduction}

This is the probability of woman success to have a child after 12 months exposure to sexual intercourse. In this study, GLM assumes that response variable follows exponential family of distribution with independent characteristics. Infertility is binary response, with which its link function is logit function linked to both linear and structure additive predictors. In the equation below, $f$ represents additive effect while $\gamma$ is the fixed effect on the explanatory variables for the parameters of interest.

$$
\eta=f(z)+\gamma(x)
$$

$\eta_{i}=f_{1}($ waman age $)+f_{2}($ states $)+\gamma_{1}($ religion $)+\gamma_{2}($ place of residence $)+\gamma_{3}($ wealth index $)+\gamma_{4}($ level of education $)+$

$\gamma_{5}($ source of water $)+\gamma_{7}($ cooking $)$

The exponential family of distribution of infertility $y_{i}$ varies from one woman to another depending on their predictor vectors $\left(x_{i}\right)$. The binary response indicates woman having a child $=1$ and not having a child $=0$. The likelihood contribution from $i^{\text {th }}$ woman infertility is binomial defined as

$$
\text { likelihood }_{i}=\pi\left(\eta_{i}\right)^{y_{i}}\left(1-\pi\left(\eta_{i}\right)\right)^{\left(1-y_{i}\right)}
$$

where $\pi\left(\eta_{i}\right)$ is the chance of woman reproducing offspring within 12 months that has the predefined covariates vector. To overcome the difficulties of heterogeneity among individuals or units may be not sufficiently described by covariates and the assumption of a strictly linear effect on the predictor may be not appropriate, so the strictly linear predictor replace by a structured additive predictor $\eta$

$$
\pi(\eta)=\frac{e^{\eta}}{1+e^{\eta}}
$$

So the likelihood function is then as follows from $i^{\text {th }}$ woman, equation 2 can now be substituted into equation 3 to give equation below

$$
\text { likelihood }_{i}=(\pi(\eta))^{y_{i}}(1-(\pi(\eta)))^{\left(1-y_{i}\right)}
$$


Since the concerned women in this study are assumed independently from one another, the likelihood function of all independent women of reproductive age at different states of Nigeria.

$$
\text { likelihood }_{i}=\prod_{i=1}^{n}(\pi(\eta))^{y_{i}}(1-(\pi(\eta)))^{\left(1-y_{i}\right)}
$$

\section{Non informative prior}

The choice of prior is a major concern for Bayesian analysis(Chao and Phillips,1998). In this study non informative priors are used because of its flexibility and that the little information is known about the variables of interest and the infertility in woman. In the absence of prior knowledge, diffuse priors are used for fixed effect parameters, that is $p(\gamma) \propto$ const. In addition, prior information was also provided on Odds ratio $=\exp (\beta)$ scale which in turns mathematically transform to the logit scale. Non informative inverse gamma priors, $\tau_{j}^{2} \sim I G\left(a_{j}, b_{j}\right) ; a, b>0$ with $a_{j}=b_{j}=0.001$ which is determined through Restricted Maximum Likelihood(REML)

$$
p\left(\beta_{j} / \tau_{j}^{2}\right) \propto \exp \left(-\frac{1}{2 \tau_{j}^{2}} \beta_{j}^{T} K_{j} \beta_{j}\right)
$$

Where $K_{j}$ is a quadratic penalty matrix that shrinks parameters towards zero or penalizes too abrupt jumps between neighbouring parameters. $K_{j}$ is rank deficient the prior for $\beta_{j}$ is partially improper(Hastie and Tisbshirani, 2000)

\section{Posterior distribution}

This distribution is obtained by multiplying the full likelihood function by the prior distribution over all parameters(Thomas and Andrea ,2008).

$$
\begin{gathered}
\text { posterior density }=\text { likelihood }_{i} \times P\left(\beta_{j} / \tau_{i}\right) \\
\text { posterior }_{i}=\prod_{i=1}^{n}\left[(\pi(\eta))^{y_{i}}(1-(\pi(\eta)))^{\left(1-v_{i}\right)}\right] \times \prod_{j=1}^{p}\left[\frac{1}{\sqrt{2 \tau_{j}^{2}}} \exp \left(-\frac{1}{2 \tau_{j}^{2}} \beta_{j}^{T} K_{j} \beta_{j}\right)\right]
\end{gathered}
$$

Since equation 8 does not have a closed form, it is numerically impossible to solve. This problem, however, is solved by numerical integration based on Monte Carlo simulation(Gibbs samplers) 
Table1. Some Numerical Characteristics of Reproduction

\begin{tabular}{|c|c|c|}
\hline Variables & Frequencies & Percentages \\
\hline \multicolumn{3}{|l|}{ Infertility } \\
\hline Have child & 1,115 & 17.09 \\
\hline No child & 5,409 & 82.91 \\
\hline \multicolumn{3}{|l|}{ Place of Residence } \\
\hline Urban & & \\
\hline Rural & 2,223 & 34.07 \\
\hline Total & 34.07 & 65.93 \\
\hline \multicolumn{3}{|l|}{ Religion } \\
\hline \multicolumn{3}{|l|}{ Christianity } \\
\hline Islam & 2,923 & 44.80 \\
\hline Traditional & 3,560 & 54.57 \\
\hline No religion & 17 & 0.26 \\
\hline Other & 20 & 0.31 \\
\hline Age & 4 & 0.06 \\
\hline \multicolumn{3}{|l|}{ Under 25} \\
\hline $26-35$ & & \\
\hline $36-45$ & 2,678 & 41.05 \\
\hline 46 above & 2,959 & 45.36 \\
\hline Level of education & 833 & 12.77 \\
\hline No education & 54 & 0.83 \\
\hline \multicolumn{3}{|l|}{ Primary } \\
\hline secondary & 2,841 & 43.55 \\
\hline Higher & 1,173 & 17.98 \\
\hline Wealth index & 2,001 & 30.67 \\
\hline Poorest & 509 & 7.80 \\
\hline \multicolumn{3}{|l|}{$\begin{array}{c}\text { Poorest } \\
\text { Poorer }\end{array}$} \\
\hline Middle & 1,264 & 19.37 \\
\hline Richer & 1,415 & 21.69 \\
\hline Richest & 1,455 & 22.30 \\
\hline Source of water & 1,288 & 19.74 \\
\hline Pipe borne water & 1,102 & 16.89 \\
\hline \multicolumn{3}{|l|}{ Well/borehole/spring } \\
\hline Rainfall/tank/bottle/sachet & 730 & 11.19 \\
\hline Others & 4,926 & 75.51 \\
\hline Cooking & 792 & 12.14 \\
\hline Electricity & 76 & 1.16 \\
\hline \multicolumn{3}{|l|}{ Petroleum product } \\
\hline Wood/coal & 38 & 0.58 \\
\hline \multirow{3}{*}{ Others } & 1,085 & 16.63 \\
\hline & 5,284 & 80.99 \\
\hline & 117 & 1.79 \\
\hline
\end{tabular}

Table 1 contains the information on response variable. infertility and selected covariates sourced from NDHS data,2015.the selected covariates are place of residence, wealth index, woman age, source of water, level of education, 
religion and cooking materials. From this table it is showed that age of the women in the study are between 15-49 years.

Table2.Estimates and posterior standard error

\begin{tabular}{l|l|l|l}
\hline Variables & Estimates & Odds ratios & $\begin{array}{l}\text { Posterior } \\
\text { std error }\end{array}$ \\
\hline Education & -0.0482871 & 0.952860 & 0.041805 \\
Religion & -0.10008 & 0.904765 & 0.066104 \\
Residence & 0.0912303 & 1.0955213 & 0.0759127 \\
Cooking & -0.00522163 & 0.9947920 & 0.0164405 \\
Water & 0.00279006 & 1.0027940 & 0.00180714 \\
Toilet & -0.0159658 & 0.9841610 & 0.0414738 \\
Wealth index & -0.0857145 & 0.9178562 & 0.0289309 \\
Constant & -1.36252 & 0.2560148 & 0.250169 \\
\hline
\end{tabular}

Table 2 contained Odds ratio of the specified socio economic variables which revealed the likelihood of unit change in specified socio economic variables. From the findings, likelihood of unit change in education, religion, cooking, type of toilet and wealth index decrease likelihood of woman having a child while that of place of residence and source of water increase likelihood of woman having a child within 12 months of sexual intercourse

\section{Nonlinear effect}

Result of the nonlinear effects of age on woman infertility is shown in Fig1. This shows that nonlinear relationship exists between the woman infertility and mother's age as against linear relationships that would have led to spurious conclusions. The likelihood of woman not reproducing offspring increase as the women advance in age. As women spend additional years in marriage, cohabiting or engaging in sexual intercourse for purpose of reproduction, the likelihood of infertility increase as oppose their expectation.

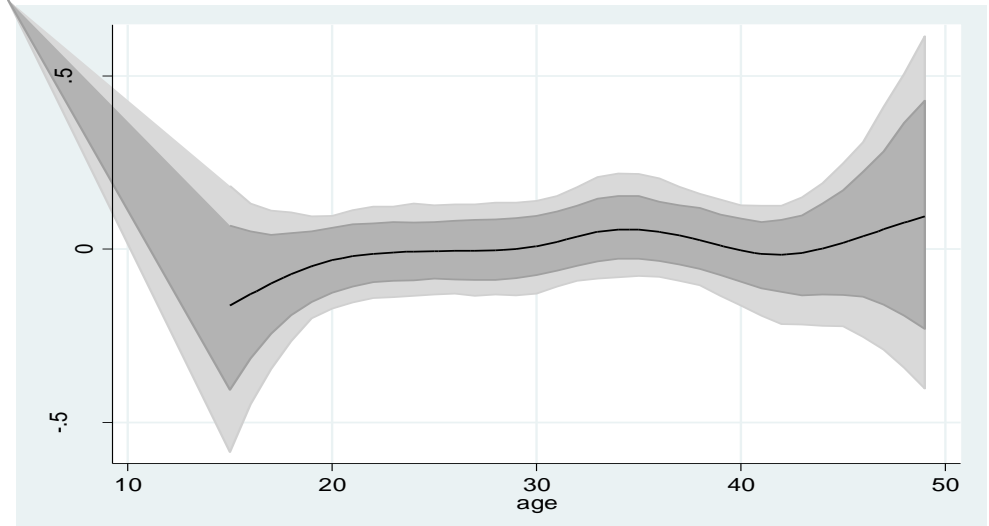

Fig1. Non linear effect of age on woman's infertility 


\section{Spatial effect}

Fig $3 \& 4$ show the spatial effect of woman infertility with its credible interval of $95 \%$. These figures present residual spatial variations of infertility within 12 months calendar year of sexual intercourse at state level of Nigeria. Fig2 shows the map of the states and 6 political region of Nigeria.

The Fig3 shows the white(grey) colour. From this, state with white colour is significant with high likelihood of woman being infertile and those state with grey colour is insignificant with the high likelihood of failure of woman to reproduce offspring within 12 months. This implies that the effect of infertility is high among women of reproductive age younger than 20 years old. Parts of Kogi, kwara, Lagos and Abia States are showing significantly high probability of woman of reproductive age not having child after 12 months of sexual intercourse. Fig4 is the residual spatial variation of woman infertility at different states of Nigeria. This graph gives better and valid interpretation of woman infertility for states in Nigeria. States with deep red shows low probability of woman not having child while those with green colour show high of it. This shows that women residing in Sokoto, Kano, Bauchi, Kaduna and other few states in the northern part of the nation are significantly likely to be infertile within a year. However, the women living in states with yellow colour are not significant likely to be infertile, for example Nasarawa state. 


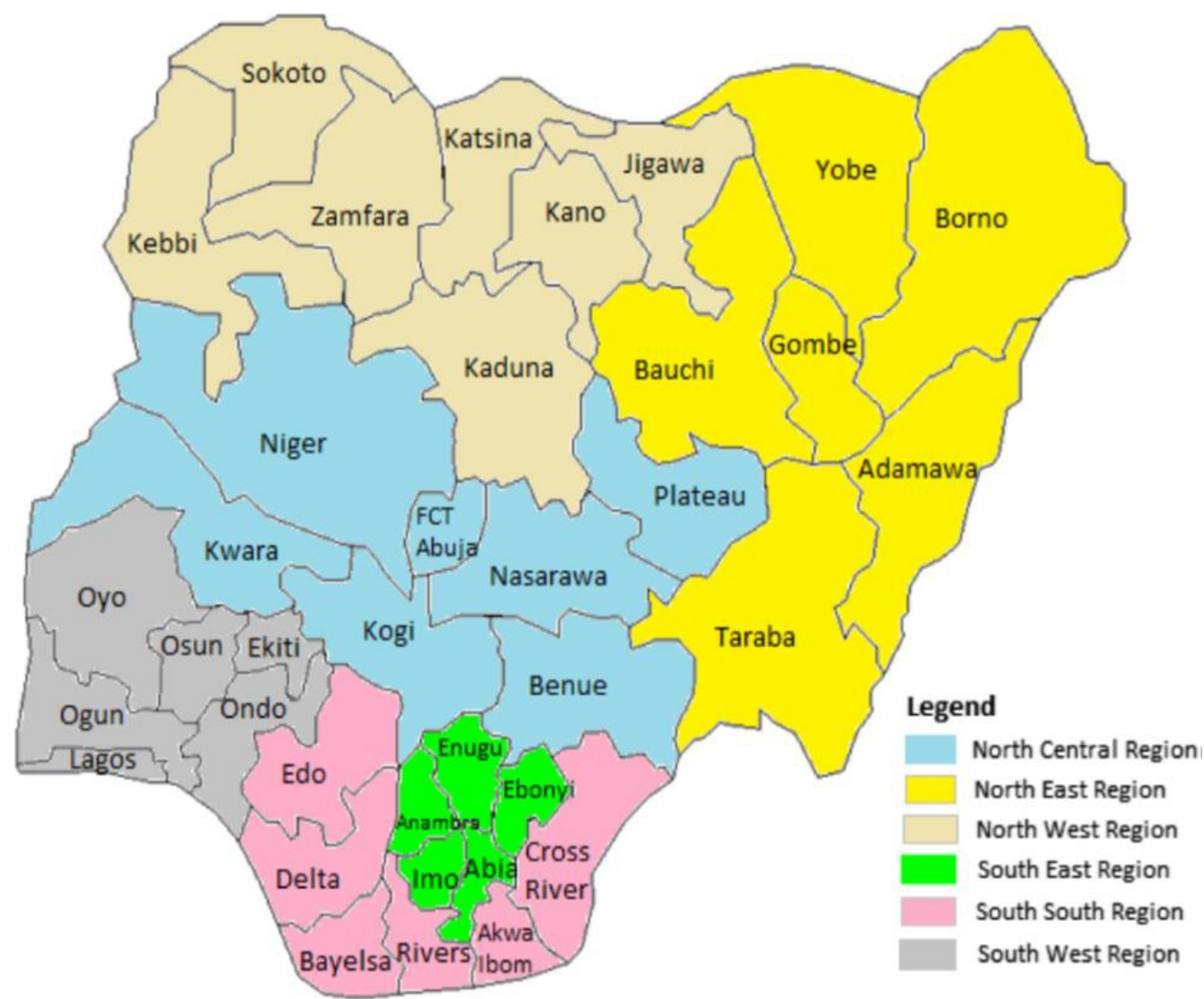

Fig. 2. Map of Nigeria show geopolitical zones and states

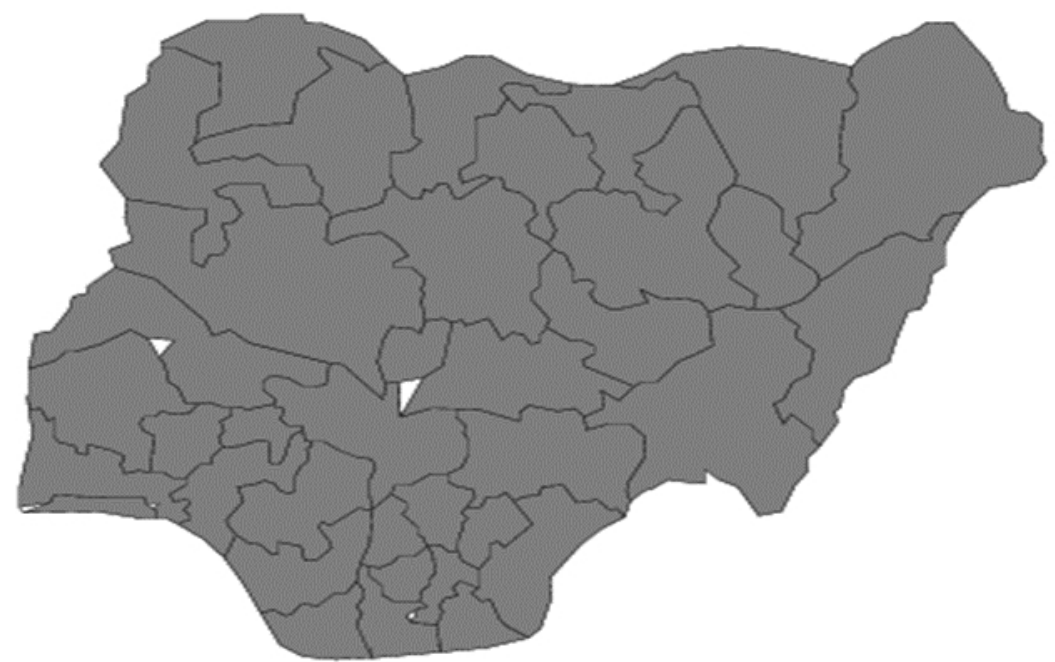

Fig3. Posterior probabilities on woman reproduction on credible level of $95 \%$ 


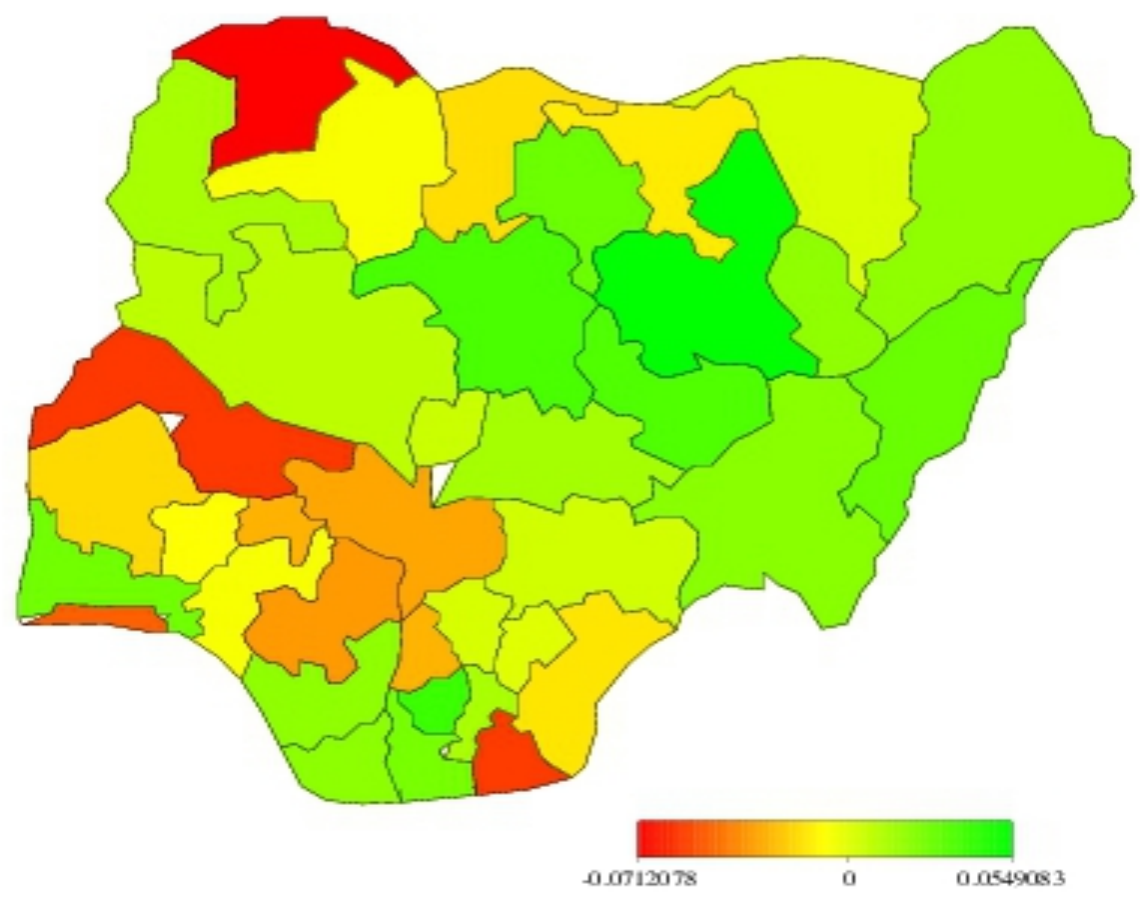

Fig3. Structured spatial effect of woman infertility

\section{Conclusion}

Infertility in general is the major health threat to woman expectation of having child. Determining risk factors of women infertility, the unit change of place of residence and source of water increase the likelihood of woman infertility while other considered risk factors reduce it within a year of exposure to sexual intercourse. Place of residence among different states is of high importance in this study, with which spatial effects of them are considered. From this study, it is revealed that women in the southern part of Nigeria are likely being infertile within 12 months of sexual relationship and that as woman age increase there is steady but increase in probability of woman unable to give birth to child. Women of reproductive age should be wary of water they drink; because polluted water and highly treated water could contribute to infertility in woman at early stage of exposure to sexual intercourse for purpose of reproducing offspring. It is evident from this work that urban and rural as places of residence contribute to likelihood of woman being infertile. The presence of factors like pollution, food like junks and not well prepared food should be given attention and atmospheric changes at different place of residence. 


\section{References:}

1. Cahill DJ, Wardle PG(2002) Management of infertility. BMJ.;3 25(7354)2: 8-32

2. Chelsea B. Polis, Carie M. Cox, Özge Tunçalp, Alexander C. McLain, and Marie E. Thoma(2017).Estimating Infertility: Conceiving of a New Approach. Global Health Now

3. Evers JL(2002). Female subfertility. Lancet.; 360(9327): 151-9.

4. Gnoth C, Godehardt E, Frank-Herrmann P, Friol K, Tigges J, Freundl $\mathrm{G}(2005)$. Definition and prevalence of subfertility and infertility. Hum Reprod; 20:1144-1147.

5. Khalaf $\mathrm{Y}(2003)$. Tubal subfertility (ABC of infertility). BMJ.; 327: 610-3

6. Olsen J, Juul S, Basso O. Measuring time to pregnancy(1998). Methodological issue to consider. Hum Reprod.; 13(7): 1751-3.

7. Wark PA, McCormack VA, Mayer D, Overton C, Little V, Nieto J, Hardiman P, Davies M, MacLean AB(2009). Ovulation-stimulation drugs and cancer risks: a long-term follow-up of a British cohort. Br J Cancer; 100(11):1824-1843.

8. Hastie, T. and Tibshirani, R., 2000: Bayesian Backfitting. Statistical Science, 15, 193-223.

9. Bongaarts John (1882). The Fertility-Inhibiting Effects of the Intermediate Fertility Variable. Studies in Family Planning.Vol. 13, No. 6/7 , pp. 179-189.DOI: 10.2307/1965445. https://www.jstor.org/stable/1965445.

10. Chao, J.C. and Phillips, P.C.B. (1998). Posterior distributions in limited information analysis of the simultaneous equations model using the Jeffreys Prior. Journal of Econometrics, 87, 49-86. 